\title{
Dual Fall, One before and other after A High Voltage Electric Injury-Case Report
}

\author{
Acharya J ${ }^{*}$, Shrestha $\mathrm{R}^{2}$, Shrestha $\mathrm{P}^{2}$ and Raghavendra Babu $\mathrm{YP}^{3}$ \\ ${ }^{1}$ Department of Forensic Medicine, Kathmandu Medical College Teaching Hospital, Kathmandu, Nepal \\ ${ }^{2}$ Department of Forensic Medicine, Institute of Medicine, Maharajgunj, Nepal \\ ${ }^{3}$ Department of Forensic Medicine and Toxicology, Institute of Medical Sciences, Koppal, India
}

${ }^{*}$ Corresponding author: Acharya J, MD, Lecturer, Department of Forensic Medicine, Kathmandu Medical College Teaching Hospital, Kathmandu, Nepal, Tel: +9779851096732, E-mail: jenashacharya65@gmail.com

Citation: Acharya J, Shrestha R, Shrestha P, Raghavendra Babu YP (2016) Dual Fall, One Before and other after A High Voltage Electric Injury- Case Report. J Forensic Sci Criminol 4(3): 304. doi: 10.15744/23489804.4.304

Received Date: May 16, 2016 Accepted Date: June 29, 2016 Published Date: June 30, 2016

\begin{abstract}
Electric injury by high voltage current is an event that has a very high rate of morbidity as well as mortality. Arcing is unique to high voltage electric injury where current is transferred between two points not in contact.

Arcing can result in temperatures reaching upto $35,000{ }^{\circ} \mathrm{F}$ and beyond. This can cause flash burns as well as circumscribed circular lesions. The mechanisms involved in electric injury deaths include ventricular fibrillations, respiratory paralysis as well as trauma following 'flinging'.
\end{abstract}

Keywords: Arcing; Electric injury; Crocodile skin; Fall

\section{Introduction}

Electric injury by high voltage current is an event that has a very high rate of morbidity as well as mortality. The mechanisms involved in electric injury deaths include ventricular fibrillations, respiratory paralysis as well as trauma following 'flinging. Arcing is another unique phenomenon attributed to high voltage electric injury where current is transferred between two points not in contact, which can result in temperatures reaching up to $35,000^{\circ} \mathrm{F}$ and beyond. This can cause flash burns as well as circumscribed circular lesions, described as 'crocodile appearance of skin" [1,2]. Fatalities could result from either burn injuries produced by the sparks or due to lethal injuries secondary to the fling due arcing. We present a case of fatality due to high voltage electric injury resulting in variety of injuries.

\section{Case Report}

As per the history provided by the investigating officer, a 35 years old male was found dead in the corridor of second floor of a four-storied house. Inquest also stated that based on a loud scream the witnesses heard coming from the roof around midnight, the family members and neighbors rushed upstairs, but on breaking the locked door to terrace, no one was found. On reconstructing the event based on crime-scene with empty bottles of alcohol lying around, the investigating officers came to a suspicion that the individual had jumped off the roof with a motive to commit suicide but accidentally came in contact with high tension electric wire $(11 \mathrm{KV})$ running alongside the terrace of his house which electrocuted and flung the body onto the balcony where he was found dead few minutes after the shout was heard by them.

At autopsy, the deceased was found to be a moderately built and nourished adult male, with indiscernible postmortem rigor and lividity. The clothes worn were tattered and partially charred. First to second degree burn-injuries with peeled off epidermis were present over right cheek, chest, abdomen, entire back, left arm, dorsal aspects of both hands, anterior aspect of left thigh and dorsal aspect of left foot.

Internal examination revealed comminuted fracture of frontal skull with adjacent localized sub-arachnoid hemorrhage over underlying left frontal lobe (Figure 1). Left maxillary central incisor and left mandibular lateral incisor were fractured and dislocated. Peri-nephric hematoma was noted in and around hilum of left kidney. All of these internal injuries seem to have been caused either by primary fall or secondarily due to 'flinging' on the balcony rather than by electric injury itself. 


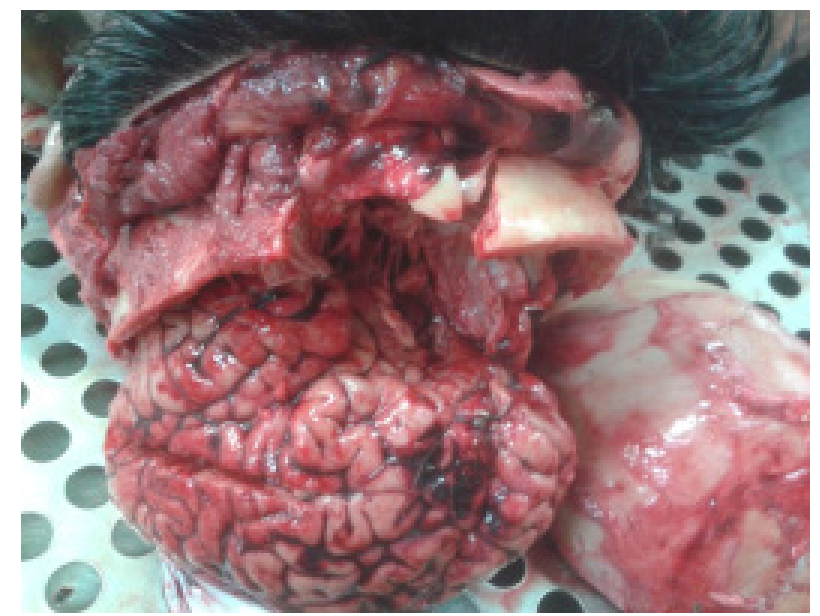

Figure 1: Fracture frontal bone with sub-arachnoid hemorrhage

Besides routinely observed burn injuries and few abrasions, contusions and superficial lacerations, well patterned multiple circular lesions were present over the torso, both arms and over left lower limb, each ranging from $0.5 \mathrm{~cm}$ to $1 \mathrm{~cm}$ in diameter. The lesions presented with thick and hard irregular margins with singeing of hair around them, which best explained "crocodile skin appearance" as found in literatures (Figure 2 and 3) [1,2].

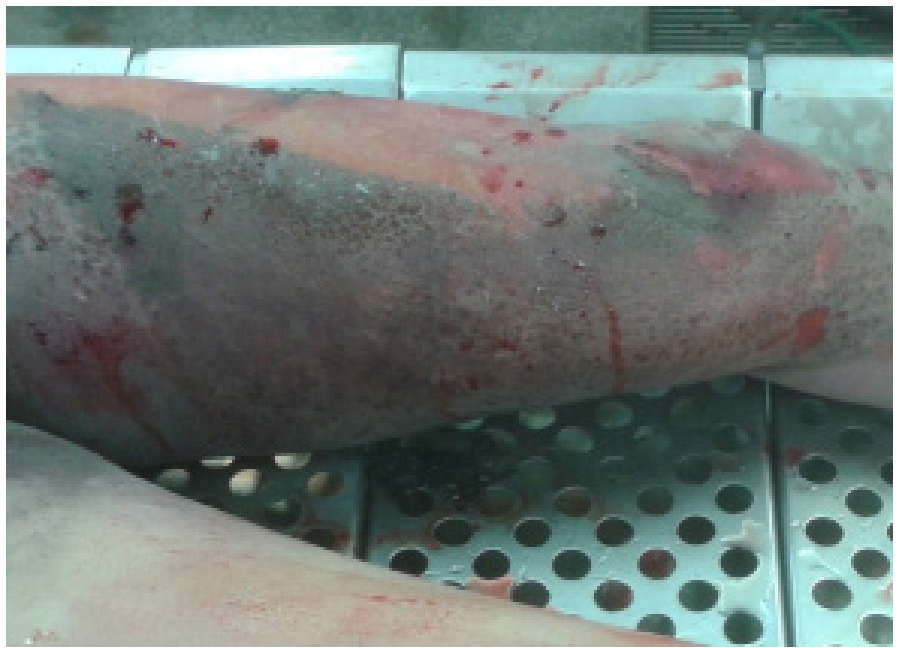

Figure 2: Circular lesions on thighs described in literatures as crocodile skin appearance

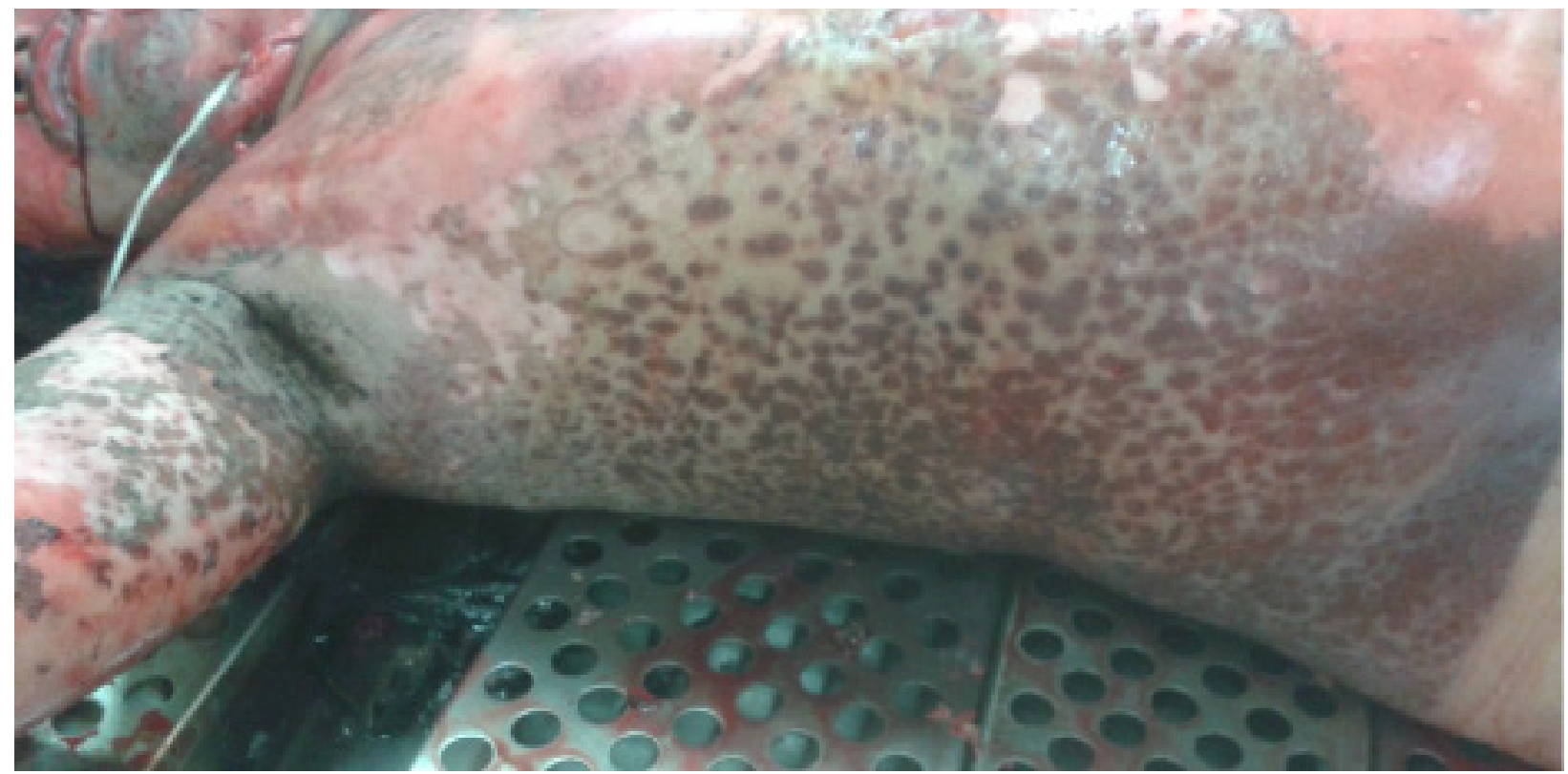

Figure 3: Multiple circular lesions with hardened margins observed in High voltage electrocution victim 


\section{Discussion}

Electric injury is not an infrequent incident anymore but there are high rate of morbidity and mortality following it [1-5]. Commonly encountered abbreviations: AC and DC stands for flow of current symbolizing Direct Current (DC) which travels in one direction, and Alternating Current (AC) that changes the direction of the electric flow. A familiar formula $\mathrm{A}=\mathrm{V} / \mathrm{R}$ expresses strength of any current, where $\mathrm{V}$ (Voltage) is constant for a given source and $\mathrm{R}$ (Resistance) is a variable dependent on resistance offered by anyone being electrocuted, which in low voltage electric injury is more or less confined to condition of skin that determines the amount of electric discharge $(\mathrm{A})$ entering the body [3].

The human body also has varying internal resistance that range from $500 \mathrm{ohms}$ for blood to $100,000 \mathrm{ohms}$ [4]. This variability in resistance $(\mathrm{R})$ of skin is brought about by factors like thickness of the keratin covering epidermis like those seen in palms, calloused parts of skin and soles of feet compared to other parts of the body. The resistance is also affected by the moisture adherent to the surface of the skin. For example; with $120 \mathrm{~V}$, resistance offered by calloused skin (a million ohm) is 10 times more than that offered by dry skin (hundred thousand ohm), 1000 times more than moist skin (1000 ohms) and 10,000 times more than moist and thin skin (100 ohms) [5]. Tissues like skin, bone, and fat are examples that have higher resistances where injuries can be demonstrated compared to blood vessels that have low resistance conducting electricity readily and sustaining less visible injuries.

But the resistance offered by skin is too less to play any vital role when it comes to high voltage electric injury. Higher the internal resistance greater is the local tissue damage due to release of heat which results in formation of the classical 'targetoid' lesion known as Joule's burn. Death is predominantly seen with low-voltage electric injury i.e. with domestic and industrial electrical use $(110-240 \mathrm{~V})$. The phenomenon of electric current following tissues with least resistance creates heat during its course and causes thermal damage as it passes through different types of tissues [6,7]. Most of the deaths from electricity are due to dysrhythmia caused as it passes through myocardium causing ventricular fibrillation or cardiac arrest in case of heart, following paralysis of inter-costal muscles and diaphragm causing respiratory arrest or rarely when the current enters through the head affecting the brain stem [3].

When it comes to high voltage electric injury, ventricular arrests are seen rather than ventricular fibrillations. Although most fatalities occur with the domestic voltage between 110 and $380 \mathrm{~V}$, death resulting from transmission lines carrying high voltage electric current for distribution $(13,800 \mathrm{~V})$ is rare and present with a unique insight into the effects of electricity on the body [8]. However, low internal resistance will result in promulgation of current with higher amperes. This can lead to development of ventricular fibrillations or respiratory paralysis. An alternating current of 100 milli-amperes for one-fifth of a second can lead to ventricular fibrillation and arrest [9].

Current transmission by means of arcing is seen when source is greater than $300 \mathrm{~V}$. Under such condition, conductive plasma is formed between source and the ground. This high-voltage arcing of the current can throw victim away from the source causing fatal injuries following a blast effect at the scene of contact $[3,10]$. This electric arc can even jump in proportion to voltage offered, example being current arcing up to $35 \mathrm{~cm}$ in $100,000 \mathrm{~V}$ compared to few $\mathrm{mm}$ in $1000 \mathrm{~V}$ [11]. The sustained burn injuries were due to arcing of the current, giving rise to the appearance of 'crocodile skin'.

The comminuted fracture of left frontal region of the skull with underlying sub arachnoid hemorrhage, injury to left kidney and external injuries confined to mostly left side of the body although hinted on its accidental causation but could not provide authors any idea as to whether injury was caused during the fall before electric injury or the fall following it. The cause of death was given as complications of burn injuries following high-voltage electrocution (11KV). Qualitative analysis showed presence of alcohol in blood and urine of the victim.

\section{References}

1. Blumenthal R (2009) A retrospective descriptive study of electrocution deaths in Gauteng, South Africa: 2001-2004. Burns 35: 888-94.

2. Manigandan G, Peranantham S, Shanmugam K (2014) Fatal High Voltage Accidental Electrocution - Two Case Reports. Int J Forensic Sci Pathol 2: 57-60.

3. Wesner ML, Hickie J (2013) Long term sequelae of electrical injury: Clinical review. Can Fam Physician 59: 935-9.

4. Wright RK, Davis JH (1980) The investigation of electrical deaths: a report of 220 fatalities. J Forensic Sci 25: 514-21.

5. Bruner JMR (1967) Haazards of electrical apparatus. Anaestesiol 28: 396-425.

6. Nagesh KR, Kanchan T, Rastogi P, Arun M (2009) Arcing injuries in fatal electric injury. Am J Forensic Med Pathol 30: 183-5.

7. Di Maio VJ, Di Maio D (2001) Forensic Pathology. 2nd ed. Boca Raton: CRC press.

8. Kumar S, Verma AK, Singh US (2013) Electric injury-related mortality in northern India - A 5-year retrospective study. Egypt J Forensic Sci 4: 1-6.

9. Saukko P, Knight B (2004) Electrical fatalities. In: Saukko P, Knight B, eds. Knight's Forensic Pathology, London: Arnold 326-38.

10. Pham TN, Gibran NS (2007) Thermal and Electrical Injuries. Surg Clin N Am 87: 185-206.

11. Sornogyi E, Tedeschi CG (1977) Injury by electrical force. In: Tedeschi CG, Eckert WG, Tedeschi LG eds: Forensic Medicine. Philadelphia, WB Saunders Co 645-76. 


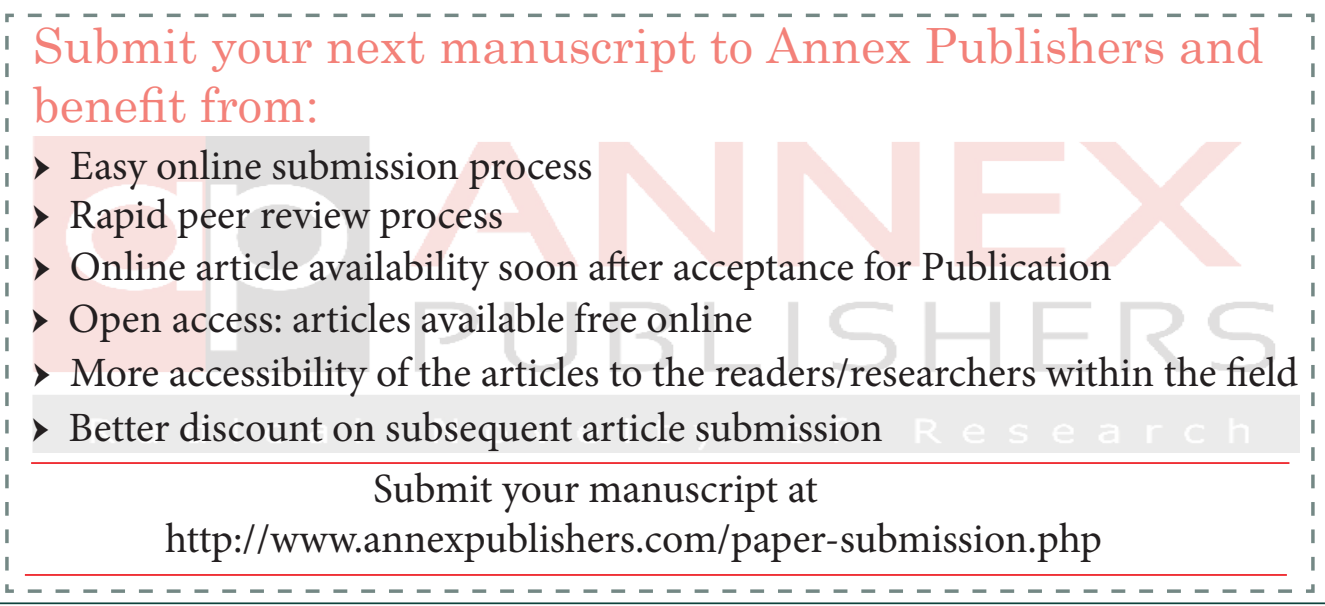

